\title{
Metallothionein is up-regulated under hypoxia and promotes the survival of human prostate cancer cells
}

\author{
MUTSUSHI YAMASAKI, TAKEO NOMURA, FUMINORI SATO and HIROMITSU MIMATA
}

\author{
Department of Oncological Science (Urology), Oita University Faculty of Medicine, \\ 1-1 Idaigaoka, Hasama-machi, Yufu-city, Oita 879-5593, Japan
}

Received April 26, 2007; Accepted July 5, 2007

\begin{abstract}
Tumor hypoxia is a common feature of several cancers, including prostate cancer, and is associated with tumor progression, acquisition of anti-apoptotic potential and therapeutic resistance. We explored hypoxia-inducible genes and examined the effect of knockdown of a target molecule with small interference RNA (siRNA) on the proliferation of human prostate cancer cells. Human prostate cancer cell lines (LNCaP and PC-3) were cultured in normoxia $\left(21 \% \mathrm{O}_{2}\right)$ or hypoxia $\left(0.5 \% \mathrm{O}_{2}\right)$. Hypoxia-inducible genes were identified by cDNA microarray analysis. Metallothionein (MT) expression was assessed by real-time RT-PCR, Western blot analysis and immunohistochemical staining. siRNA was transfected to knock down MT expression, and the cell cycle and apoptosis were evaluated by flow cytometry analysis. In cDNA microarray analysis, 22 genes (including MT) were up-regulated under hypoxia. MT-1X and MT-2A were upregulated in real-time RT-PCR. In particular, MT-2A was increased 3-fold in LNCaP and 8-fold in PC-3. The siRNAMT-2A treatment resulted in a $20 \%$ inhibition of cell growth and induced apoptosis in both LNCaP and PC-3. In human prostate tissue, intense staining of MT was observed in cancer cells and residual cancer cells after androgen ablation therapy, while normal tissue was only stained in patches. In conclusion, MT was up-regulated under hypoxia in prostate cancer cells and overexpressed in prostate cancer tissue and residual cancer cells after androgen ablation therapy. As down-regulation of MT by siRNA inhibited cell growth and induced cell death, MT may be a new molecular target for the treatment of human prostate cancer.
\end{abstract}

\section{Introduction}

Prostate cancer is one of the most common malignancies diagnosed and treated in men in the Western countries (1). Androgen ablation therapy plays a central role in the treat-

Correspondence to: Dr Mutsushi Yamasaki, Department of Oncological Science (Urology), Oita University Faculty of Medicine, 1-1 Idaigaoka, Hasama-machi, Yufu-city, Oita 879-5593, Japan

E-mail: mutsushi@med.oita-u.ac.jp

Key words: metallothionein, hypoxia, prostate cancer, siRNA ment of patients with advanced prostate cancer. However, approximately $15 \%$ of patients do not respond to hormone manipulation, and the majority relapses within 2-3 years from treatment. Despite recent advances in chemotherapy regimens, hormone refractory prostate cancer remains incurable. Although major advances in molecular biology have provided new insights into etiology and biology of prostate cancer, pathways and molecules that contribute to the growth and survival of cancer cells are not entirely understood. Therefore, identification of such molecules and novel therapeutic strategies targeting them in advanced prostate cancer is required.

Cancer cells often encounter a hypoxic environment during tumor growth and progression. This tumor hypoxia is a common feature of several cancers and is associated with tumor progression, acquisition of anti-apoptotic potential, therapeutic resistance and poor outcome $(2,3)$. Moreover, hypoxia is an independent prognostic factor regardless of treatment modality in gastrointestinal, cervical, head-andneck carcinoma and soft tissue sarcoma (4-7). Tumor hypoxia is also correlated with a poor clinical outcome in prostate cancer (8-10). Movsas et al revealed the presence of hypoxic regions in human prostate tissue with the use of custom-made Eppendorf electrodes (11). The gene expression patterns change dramatically in a hypoxic environment. Therefore, we hypothesized that hypoxia inducible genes may promote the survival of a more aggressive cell phenotype and suppression of these genes may be useful for new therapeutic strategy. To test our hypothesis, hypoxia inducible genes expression in prostate cancer cells was investigated using cDNA microarrays. Among the differentially expressed genes, the metallothionein (MT) gene family encodes proteins that are involved in metal detoxification, chemoresistance, cell proliferation, apoptosis, essential metal homeostasis (including the regulation of a high concentration of zinc in the prostate gland), and protection against several types of cell damage (12-14). Therefore, a markedly up-regulated MT gene was chosen for further analysis. We investigated the effect of MT suppression by siRNA on prostate cancer cells growth and the expression of MT in human prostate cancer tissues.

This is the first report demonstrating that MT is upregulated under hypoxia in prostate cancer cells and involved in the acceleration of cell proliferation and inhibition of cell death. 


\section{Materials and methods}

Cell lines and culture conditions. The human prostate cancer cell lines, LNCaP and PC-3, were purchased from the American Type Culture Collection (ATCC, Rockville, MD). LNCaP cells were cultured in RPMI-1640 (Sigma-Aldrich, St. Louis, MO) supplemented with $15 \%$ fetal bovine serum (Sigma-Aldrich), $50 \mu \mathrm{g} / \mathrm{ml}$ streptomycin and $50 \mathrm{IU} / \mathrm{ml}$ penicillin (Gibco, Grand Island, NY) at $37^{\circ} \mathrm{C}$ in a humidified $5 \% \mathrm{CO}_{2} / 95 \%$ air environment. PC-3 cells were cultured in Minimum Essential Medium Eagle (Sigma-Aldrich) containing $10 \%$ newborn calf serum (Bio-Whittaker, Walkersville, MD), $50 \mu \mathrm{g} / \mathrm{ml}$ streptomycin and $50 \mathrm{IU} / \mathrm{ml}$ penicillin (Gibco) at $37^{\circ} \mathrm{C}$ in a humidified $5 \% \mathrm{CO}_{2} / 95 \%$ air environment. In hypoxia experiments, cells were cultured at $37^{\circ} \mathrm{C}$ in an Anaerobic Jar (Sanshin Industrial Co., Yokohama, Japan) with $5 \% \mathrm{CO}_{2}, 94.5 \% \mathrm{~N}_{2}$ and $0.5 \% \mathrm{O}_{2}$.

Total-RNA extraction. Total-RNA was isolated using TRIzol ${ }^{\circledR}$ Reagent (Invitrogen Life Technologies, Carlsbad, CA) according to the manufacturer's instructions.

cDNA microarray analysis. cDNA microarray analysis was performed using the Gene Navigator ${ }^{\circledR}$ cDNA Array System (Toyobo, Osaka, Japan). Two samples from LNCaP cells under normoxia and hypoxia for $24 \mathrm{~h}$ were used in this analysis. The mRNA was purified from total-RNA using a MagExtractor ${ }^{\circledR}$-mRNA-Kit. Biotin-labeled cDNA was then prepared from the mRNA with biotin-dUTP and the Gene Navigator cDNA Amplification System. The labeled cDNA was hybridized to a Gene Navigator cDNA array filter in PerfectHyb ${ }^{\circledR}$ hybridization. Signals from the 550 cancerrelated genes and 11 housekeeping genes on the human cancer array were visualized using the Gene Navigator ${ }^{\circledR}$ Imaging High Chemilumi. The complete list of genes on this array filter is available at the Toyobo web site (http:// www .toyobo.co.jp/seihin/xr/product/genenavi2/genename2 $\mathrm{h}$ tml).

Real-time RT-PCR. Total-RNA $(1 \mu \mathrm{g})$ was synthesized into cDNA using random hexamers and murine leukemia virus reverse transcriptase (Roche Molecular Systems, Branchburg, NJ) according to the manufacturer's instructions. Each cDNA sample $(2 \mu \mathrm{l})$ was amplified using LightCycler-FastStart DNA Master SYBR Green I (Roche Diagnostics GmbH, Mannheim, Germany) on a LightCycler ${ }^{\mathrm{TM}}$ (Roche Diagnostics Corp., Indianapolis, IN). Each cycle consisted of denaturation at $95^{\circ} \mathrm{C}$ for $15 \mathrm{sec}$, annealing at $55^{\circ} \mathrm{C}$ for $5 \mathrm{sec}$ and polymerization at $72^{\circ} \mathrm{C}$ for $10 \mathrm{sec}$. The sequences of the primers were as follows (12): MT-1A forward (5'-CTCGAAATGGACCC CAACT-3'), MT-1A reverse (5'-ATATCTTCGAGCAGGGC TGTC-3'), MT-1X forward (5'-TCTCCTTGCCTCGAAATG GAC-3'), MT-1X reverse (5'-GGGCACACTTGGCACAG C-3'), MT-2A forward (5'-CCGACTCTAGCCGCCTCTT-3'), MT-2A reverse (5'-GTGGAAGTCGCGTTCTTTACA-3'), MT-3 forward (5'-ATGGACCCTGAGACCTGCCCCTG-3'), MT-3 reverse (5'-TCACTGGCAGCAGCT GCACTTCTC-3'), B-actin forward (5'-AAAGACCTGTACGCCAACAC-3') and B-actin reverse (5'-GTCATACTCCTGCTTGCTGAT-3'). $\beta$-actin was used as an endogenous control to normalize each sample. The experiment was performed by three independent experiments with duplicate.

Protein extraction and Western blot analysis. Whole cell extracts were obtained with M-PER ${ }^{\circledR}$ Mammalian Protein Extraction Reagent containing Halt ${ }^{\mathrm{TM}}$ protease inhibitor cocktail (Pierce, Rockford, IL). Protein concentration was determined with the Coomassie ${ }^{\circledR}$ Plus Protein Assay Reagent Kit (Pierce). Western blotting to detect MT was performed as described by Mizzen et al (15). Cell proteins were electrophoresed on $20 \%$ SDS-polyacrylamide gels and transferred to polyvinylidene difluoride (PVDF) membranes (Millipore Corp., Bedford, MA) in transfer buffer containing $2 \mathrm{mM}$ $\mathrm{CaCl}_{2}$. Following transfer, the membranes were incubated in $2.5 \%$ glutaraldehyde for $1 \mathrm{~h}$. The membranes were blocked in $0.1 \%$ Tween-20 and $0.1 \mathrm{~mol} / 1$ phosphate-buffered saline (T-PBS) containing 5\% skim milk for $1 \mathrm{~h}$ at room temperature and then incubated overnight at $4{ }^{\circ} \mathrm{C}$ in mouse monoclonal anti-MT (E9) antibody (1:100) (Dako Cytomation, Inc., Carpinteria, CA) and rabbit polyclonal anti-actin antibody (1:500) (Santa Cruz Biotechnology, Inc., Santa Cruz, CA). After washing with T-PBS, the membranes were incubated with the corresponding secondary antibodies that were conjugated with horseradish peroxidase (HRP), for $1 \mathrm{~h}$ at room temperature. Immunoreactive bands were visualized with ECL Plus Western Blotting Detection Reagents (Amersham Biosciences, Piscataway, NJ).

Small interference RNA (siRNA) treatment. siRNA against the MT-2A cocktail (siRNA-MT2A) or the negative control siRNA cocktail (siRNA-NC) (B-Bridge International, Inc., Sunnyvale, CA) was transfected into LNCaP and PC-3 cells using the Nucleofector ${ }^{\mathrm{TM}}$ (Amaxa $\mathrm{GmbH}$, Cologne, Germany) according to the manufacturer's instructions. Briefly, $2 \times 10^{6}$ LNCaP or PC-3 cells were resuspended in solutions $\mathrm{R}$ (LNCaP) or V (PC-3); after adding $5 \mu \mathrm{g}$ of siRNA the cells were electroporated using the T-9 (LNCaP) or T-13 (PC-3) program.

Cell growth analysis. LNCaP and PC-3 cells, transfected with siRNA-MT2A or with siRNA-NC or without siRNA (control), were seeded onto 6-well plates at a density of $2 \times 10^{5}$ cells/well $(\mathrm{LNCaP})$ or $2.5 \times 10^{5}$ cells/well (PC-3) and incubated at normoxia for $24 \mathrm{~h}$. After the medium was changed to remove cells killed by electroporation, the plates were incubated at normoxia or hypoxia for an additional $72 \mathrm{~h}$. Cells were trypsinized, collected separately from each well, and counted at $0,24,48$ and $72 \mathrm{~h}$ after changed medium. The average number of cells was calculated from three independent experiments, repeated in duplicate.

Flow cytometry analysis. LNCaP and PC-3 cells, transfected with siRNA-MT2A or with siRNA-NC or without siRNA (control), were seeded onto 6-well plates at a density of $5 \times 10^{5}$ cells/well and incubated under normoxia for $24 \mathrm{~h}$. After changing the medium, the plates were incubated at normoxia or hypoxia for $48 \mathrm{~h}$. The cells were collected by trypsinization, washed with PBS, fixed with $70 \%$ methanol, and stored at $-20^{\circ} \mathrm{C}$. The fixed cells were incubated with $10 \mu \mathrm{g} /$ $\mathrm{ml}$ RNase A (Sigma-Aldrich) for $30 \mathrm{~min}$ at room temperature 
Table I. List of genes up-regulated under hypoxia.

\begin{tabular}{llrr}
\hline Gene name & \multicolumn{1}{c}{ Classification } & $\begin{array}{c}\text { Signal intensity } \\
\text { (under normoxia) }\end{array}$ & Ratio \\
\hline ARC (apoptosis repressor with a CARD domain) & Tumor suppressor genes/Apoptosis & 6344.1 & 2.86 \\
Nip3 (BNIP3) & Tumor suppressor genes/Apoptosis & 3140.2 & 6.82 \\
GADD34 & Tumor suppressor genes/Apoptosis & 196.7 & 3.06 \\
DCC (deleted in colorectal cancer) & Tumor suppressor genes/Apoptosis & 28.1 & 8.21 \\
PCTAIRE-3 & Cell cycle proteins & 341.3 & 2.43 \\
Cyclin D1 (CYL1) & Cell cycle proteins & 4241.7 & 2.48 \\
P27Kip1 & Cell cycle protein & 3327.7 & 3.69 \\
P57Kip2 & Cell cycle protein & 684.0 & 4.79 \\
c-fos & Regulatory transcription factors & 350.3 & 14.46 \\
c-jun & Regulatory transcription factors & 9031.0 & 6.05 \\
Egr-1 & Regulatory transcription factors & 1192.1 & 2.10 \\
E2F3 & Regulatory transcription factors & 226.9 & 2.20 \\
VEGF-b & Growth factor and hormones & 876.5 & 3.64 \\
Midkine & Growth factor and hormones & 2909.1 & 2.39 \\
PLC- $\gamma$ 1 & Signaling intermediates & 684.0 & 2.97 \\
HSP27 & Signaling intermediates & 30664.0 & 3.34 \\
R-Ras & GDP/GTP binding proteins & 668.7 & 3.06 \\
Vinculin & Cell adhesion proteins & 2057.2 & 2.40 \\
c-mos & Protein kinases & 176.9 & 2.86 \\
VEGF & Growth factor and hormones & 910.1 & 6.23 \\
3-Methyladenine DNA glycosylase & Metabolic enzyme & 2213.1 & 2.13 \\
Metallothionein & Metabolic enzyme & 3516.7 & 6.96 \\
\hline
\end{tabular}

and stained with $50 \mu \mathrm{g} / \mathrm{ml}$ propidium iodide (Sigma-Aldrich) for $30 \mathrm{~min}$ at room temperature. Relative DNA content was determined with a FACSCalibur ${ }^{\mathrm{TM}}$ flow cytometer (BectonDickinson, San Jose, CA). The cell cycle distribution and sub-G1 region (apoptotic cells) were calculated using CellQuest ${ }^{\mathrm{TM}}$ software (Becton-Dickinson).

Apoptosis detection. Cleaved anti-poly(ADP-ribose) polymerase (PARP) was detected by Western blot analysis. Cell proteins were electrophoresed on 4-12\% SDS-polyacrylamide gels and transferred to PVDF membranes (Millipore Corp.). Following transfer, the membranes were blocked in T-PBS containing 5\% skim milk for $1 \mathrm{~h}$ at room temperature and incubated overnight at $4^{\circ} \mathrm{C}$ in rabbit anti-PARP antibody (1:1000) (Cell Signaling Technology, Inc., Beverly, MA) and mouse monoclonal anti- $\beta$-tubulin antibody $(1: 10000)$ (Chemicon, Temecula, CA). After washing with T-PBS, the membranes were incubated with the corresponding secondary antibodies that were conjugated with HRP for $1 \mathrm{~h}$ at room temperature. Immunoreactive bands were visualized with the ECL Plus Western Blotting Detection Reagents (Amersham Biosciences).

Immunohistochemical staining. The paraffin-embedded tissue sections obtained from prostate cancer patients $(\mathrm{n}=40)$ undergoing radical prostatectomy, with $(n=20)$ and without $(n=20)$ neoadjuvant androgen ablation therapy were studied. The androgen ablation therapy was performed by combined androgen blockade consisted of an anti-androgen and a luteinizing hormone-releasing hormone agonist. Tissue sections were cut from paraffin-embedded blocks and placed on silicone-coated slides. After deparaffinization in xylene and rehydration using graded alcohol solutions, the sections were incubated in $0.3 \% \mathrm{H}_{2} \mathrm{O}_{2}$ for 10 min to inactivate endogenous peroxidase, followed by washing in phosphate-buffered saline (PBS). To block non-specific binding to sections and eliminate non-specific staining, $10 \%$ normal goat serum in PBS was applied to the sections and incubated for $10 \mathrm{~min}$. The slides were then incubated with mouse monoclonal anti-MT (E9) antibody (1:100) (Dako Cytomation, Inc.) overnight at $4^{\circ} \mathrm{C}$, followed by washing in PBS. The slides were incubated with anti-mouse Dako Cytomation EnVision ${ }^{+\oplus}$ System-HRP Labelled Polymer (Dako Cytomation, Inc.) for $30 \mathrm{~min}$ at room temperature. After washing with PBS, the color was developed using the Dako Cytomation Liquid DAB Substrate Chromogen System (Dako Cytomation, Inc.). The sections were counterstained with hematoxylin, washed in tap water, and mounted with aqueous mounting media. Assessment of immunohistochemical staining was scored by two observers without prior knowledge of each patient's clinicopathological information. In each case, MT staining was evaluated in benign epithelium cells and cancer cells. There was some staining heterogeneity in the majority of tumors and the score was based on the most intensively stained area within each specimen. The staining intensity was scored as negative, weak, moderate or strong. For statistical 
Table II. The genes down-regulated under hypoxia.

\begin{tabular}{|c|c|c|c|}
\hline Gene name & Classification & $\begin{array}{l}\text { Signal intensity } \\
\text { (under normoxia) }\end{array}$ & Ratio \\
\hline p53 & Tumor suppressor genes/Apoptosis & 8562.9 & 0.42 \\
\hline FADD (MORT1) & Tumor suppressor genes/Apoptosis & 9813.2 & 0.35 \\
\hline FLIP (FLICE inhibitory protein) & Tumor suppressor genes/Apoptosis & 11439.9 & 0.40 \\
\hline MLH1 & Tumor suppressor genes/Apoptosis & 2253.1 & 0.37 \\
\hline PMS1 & Tumor suppressor genes/Apoptosis & 1371.8 & 0.41 \\
\hline Elongin C (RNA pol II elongation factor SIII) & Tumor suppressor genes/Apoptosis & 2180.2 & 0.36 \\
\hline MEN1 (Menin coding gene) & Tumor suppressor genes/Apoptosis & 5515.7 & 0.47 \\
\hline CEA & Tumor suppressor genes/Apoptosis & 690.7 & 0.45 \\
\hline Cyclin B1 & Cell cycle proteins & 11283.6 & 0.22 \\
\hline $\mathrm{HGF}$ & Growth factor and hormones & 761.7 & 0.26 \\
\hline TNF- $\alpha$ & Growth factor and hormones & 617.7 & 0.42 \\
\hline TGFß-RII & Membrane receptors & 441.8 & 0.36 \\
\hline Ras-GAP & Signaling intermediates & 5022.2 & 0.46 \\
\hline Integrin $\alpha 2$ (CD49B) & Cell adhesion proteins & 1006.7 & 0.30 \\
\hline Integrin $\alpha \mathrm{X}$ (CD11c) & Cell adhesion proteins & 167.3 & 0.37 \\
\hline Connexin 26 & Cell adhesion proteins & 485.7 & 0.39 \\
\hline DC-CK1 (PARC, MIP-4) & Growth factor and hormones & 681.1 & 0.46 \\
\hline IL-1 $\alpha$ (Mouse IL-1) & Growth factor and hormones & 919.4 & 0.46 \\
\hline Deoxycytidine kinase & Enzyme & 611.1 & 0.36 \\
\hline CTP synthetase & Enzyme & 11385.1 & 0.36 \\
\hline Maspin & Tumor suppressor genes/Apoptosis & 2211.6 & 0.42 \\
\hline Topo II (DNA topoisomerase II) & Drug resistance & 12792.7 & 0.35 \\
\hline Bub1b (Mad3L) & Drug resistance & 1774.1 & 0.41 \\
\hline
\end{tabular}

A

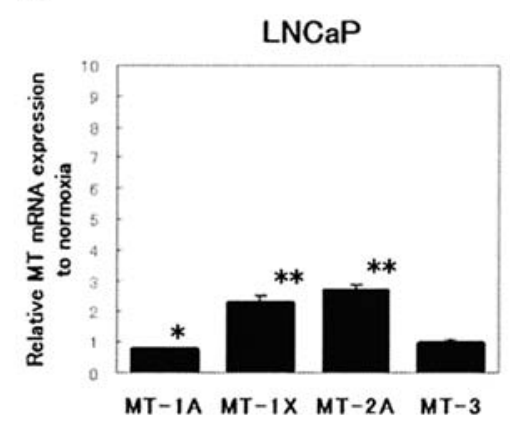

Tumor suppressor genes/Apoptosis

Tumor suppressor genes/Apoptosis

Tumor suppressor genes/Apoptosis

Tumor suppressor genes/Apoptosis

Cell cycle proteins

Growth factor and hormones

Growth factor and hormones

Signaling intermediates

Cell adhesion proteins

Cell adhesion proteins

Enzyme

Enzyme

Drug resistance

Drug resistance
0.42

0.40

0.37

.41

0.47

0.45

.22

0.42

0.36

0.46

0.30

0.37

0.39

0.46

0.46

0.36

0.36

0.42

0.41

Figure 1. Change of MT expression by hypoxia in LNCaP and PC-3 cells. (A) mRNA expression of MT isoforms under hypoxia (24 h) was determined by real-time PCR. The bars show expression of each MT isoform under hypoxia relative to normoxia. $\beta$-actin was used as an endogenous control to normalize each sample. Each bar is the mean \pm SD from three independent experiments with duplicate $\left({ }^{*} \mathrm{p}<0.05\right.$ versus normoxia; ${ }^{* *} \mathrm{p}<0.005$ versus normoxia). (B) Expression of MT protein under normoxia and hypoxia $(48 \mathrm{~h})$ was determined by Western blotting.

analysis, two groups were considered: negative and weak staining level were considered low-intensity staining, moderate and strong staining level were considered high-intensity staining.

Statistical evaluation. Values were expressed as means \pm SD. Statistical analysis was performed using the Student's t-test and Mann-Whitney U-test. Relationships between qualitative variables were determined using the $\chi^{2}$ test. Values of $\mathrm{p}<0.05$ were considered statistically significant.

\section{Results}

cDNA microarray analysis. Genes that are differentially expressed under hypoxia were identified by cDNA microarray analysis of 550 cancer-related genes. In LNCaP cells under hypoxia, 22 genes were up-regulated (Table I) and 23 genes were down-regulated (Table II) when compared with normoxic LNCaP cells. Remarkable up-regulations (a ratio over 5.0) were noted in 6 genes (Nip3, DCC, c-fos, c-jun, VEGF and metallothionein). 
A

\begin{tabular}{|c|c|c|c|c|c|c|c|c|c|c|c|c|}
\hline & \multicolumn{6}{|c|}{ LNCaP } & \multicolumn{6}{|c|}{$P C-3$} \\
\hline & \multicolumn{3}{|c|}{ normoxia } & \multicolumn{3}{|c|}{ hypoxia } & \multicolumn{3}{|c|}{ normoxia } & \multicolumn{3}{|c|}{ hypoxia } \\
\hline & C & $\mathbf{N}$ & $s$ & C & $\mathrm{N}$ & $s$ & c & $\mathbf{N}$ & $\mathrm{s}$ & C & $\mathrm{N}$ & $\mathrm{s}$ \\
\hline MT & & & & - & & 2 & 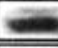 & & & & & nis \\
\hline ctin & $=$ & & & & & & & & & & & \\
\hline
\end{tabular}

B
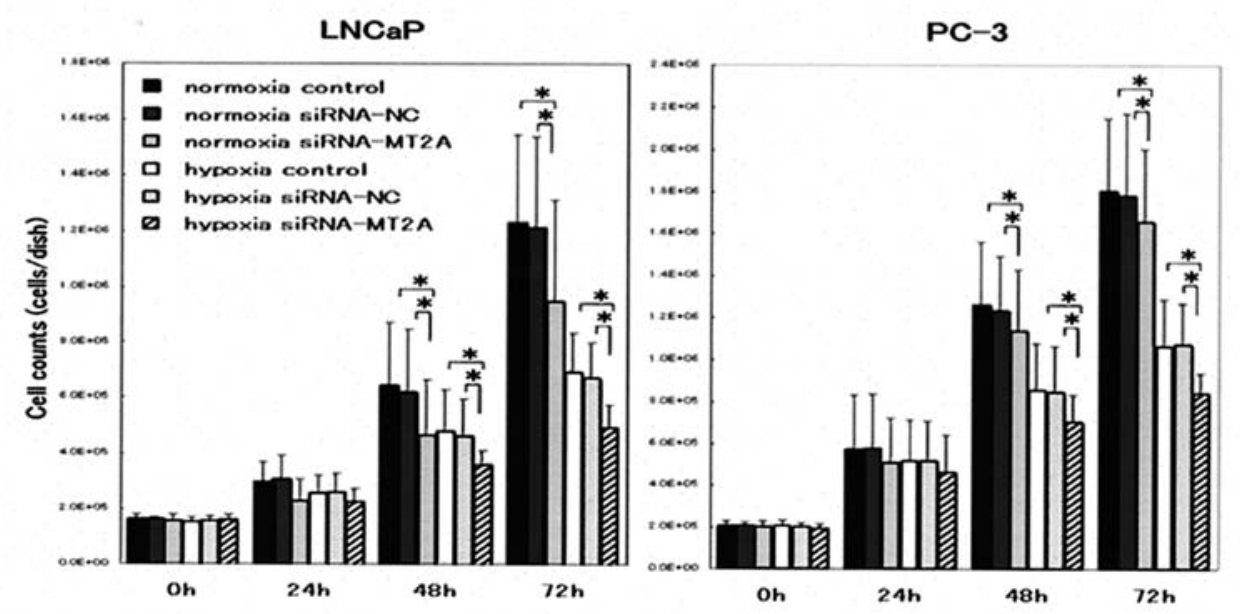

C
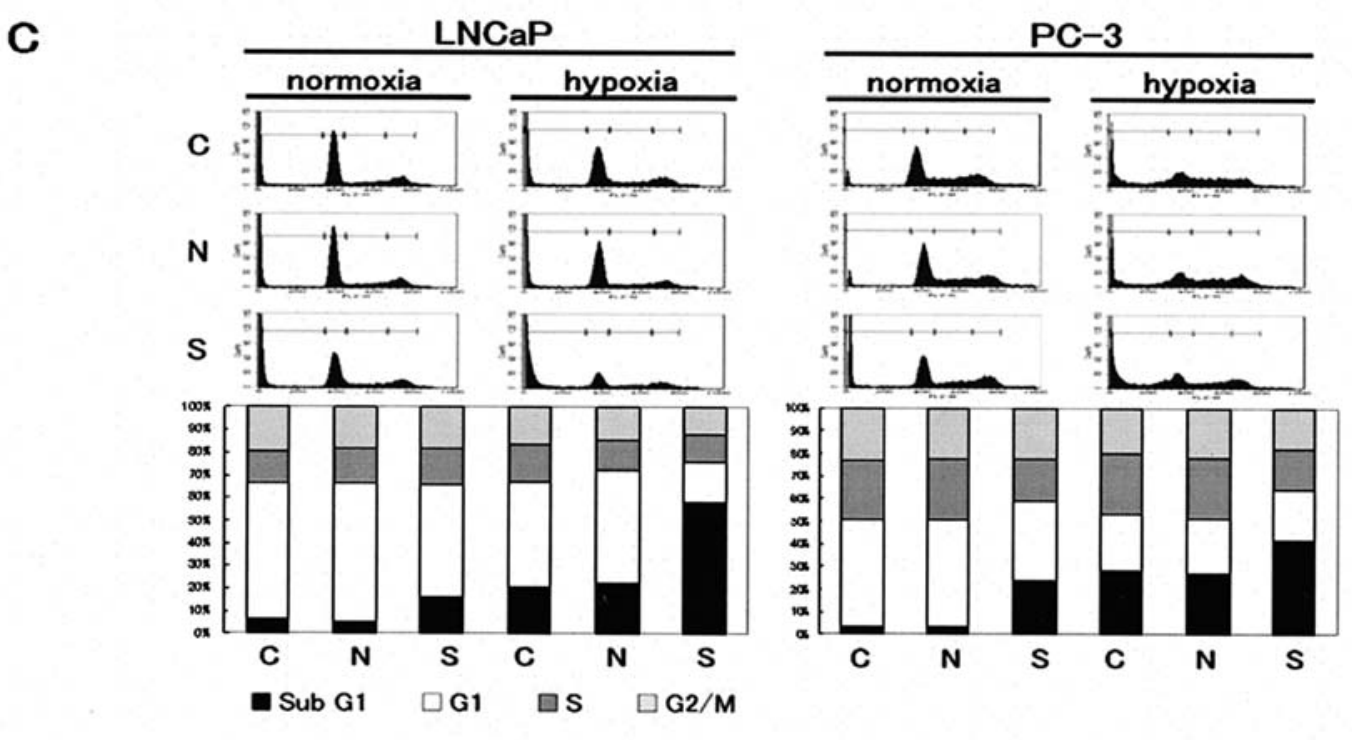

D

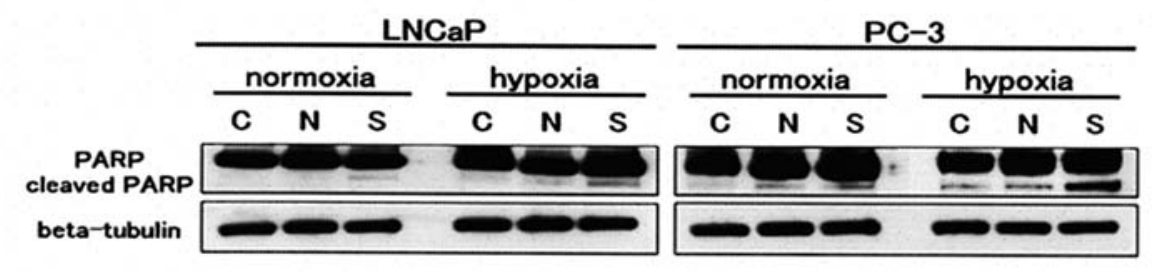

Figure 2. Cell growth inhibition and apoptosis induction caused by down-regulation of MT-2A. LNCaP and PC-3 cells transfected with siRNA or not were incubated at normoxia for $24 \mathrm{~h}$. After changed medium, each sample was incubated normoxia or hypoxia for an additional $72 \mathrm{~h}$. C, control; N, siRNA-NC (negative control); S, siRNA-MT2A. (A) Down-regulation of MT by siRNA was determined at 48 h after changed medium. (B) Cell growth inhibition by down-regulation of MT-2A. The horizontal axis shows the time from changed medium. Each bar is the mean \pm SD from three independent experiments with duplicate ( ${ }^{*} \mathrm{p}<0.05$ versus control). (C) Change of cell cycle population by down-regulation of MT-2A. (D) Poly(ADP-ribose) polymerase (PARP) cleavage by down-regulation of MT-2A was detected at $48 \mathrm{~h}$ after changed medium.

MT mRNA and MT protein expressions under hypoxia in prostate cancer cell lines. The expression of functional MT isoforms in human prostate cancer tissue or cell lines (12) was analyzed using real-time PCR (Fig. 1A). Expression of MT-1A mRNA was significantly decreased $(\mathrm{p}<0.05)$ in both LNCaP and PC-3 cells. In contrast, MT-1X and MT-2A transcripts were significantly up-regulated $(\mathrm{p}<0.005)$ under hypoxia in LNCaP and PC-3 cells. In particular, MT-2A mRNA levels increased about 3-fold in LNCaP cells and about 8 -fold in PC-3 cells. MT protein expression was confirmed by Western blot analysis using a mouse monoclonal anti-MT antibody that did not discriminate between MT isoforms. MT 


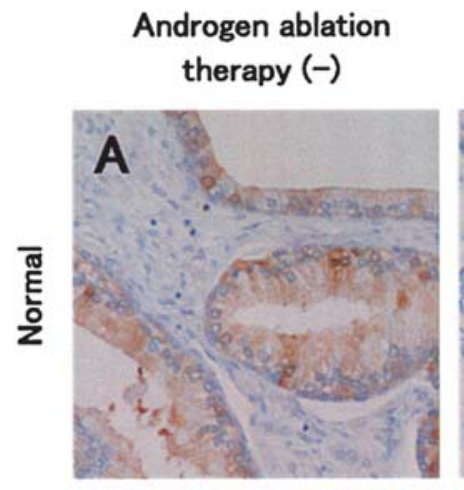

\section{Androgen ablation therapy $(+)$}
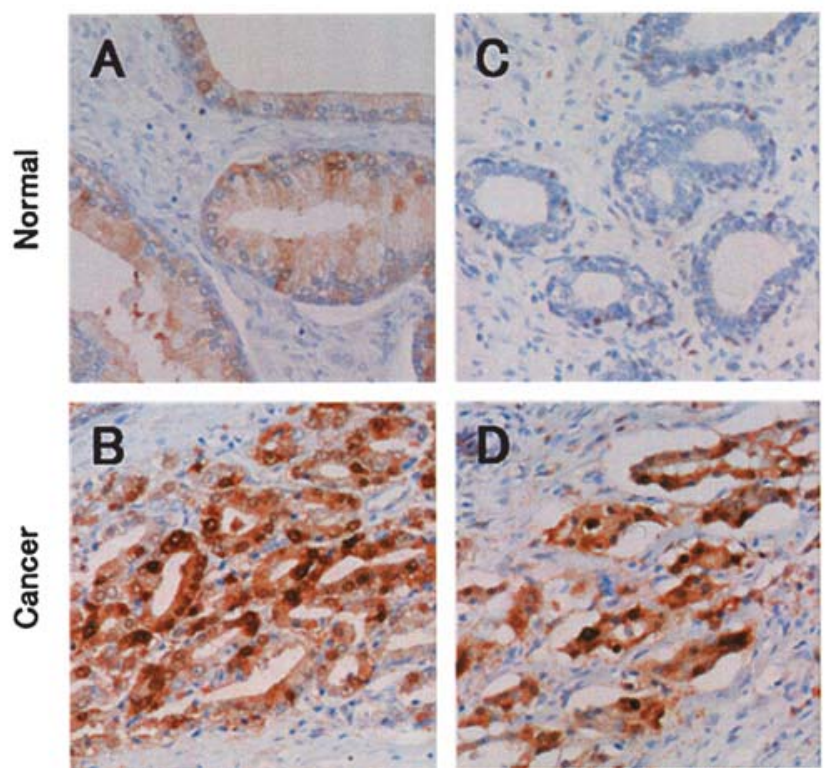

E

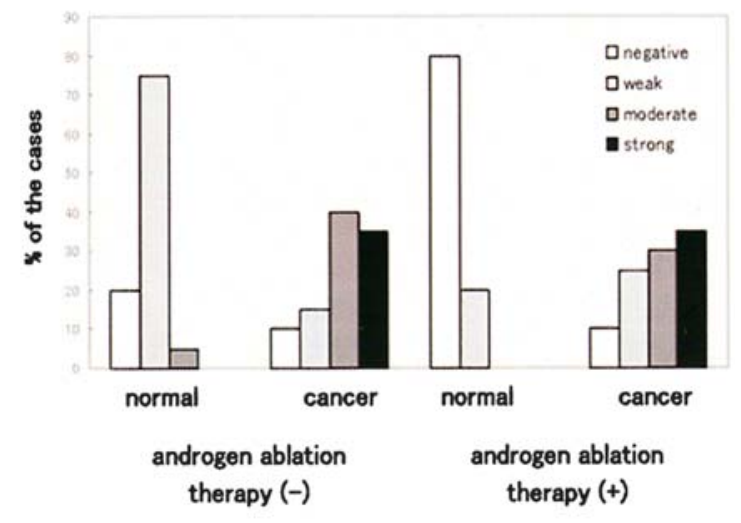

Figure 3. MT expression in human prostate tissue. The tissue sections obtained from PC patients undergoing radical prostatectomy ( $=40$ ), with ( $=20$ ) and without $(n=20)$ neoadjuvant androgen ablation therapy were studied. (A) Normal prostate tissue; (B) Prostate cancer tissue (Gleason score $3+4=7$, moderately differentiated); (C) Normal prostate tissue after androgen ablation therapy; (D) Prostate cancer tissue after androgen ablation therapy (Gleason score $3+3=6$, moderately differentiated); (E) The overall distribution of MT staining intensity.

proteins were expressed much more in the LNCaP cells than in PC-3 cells under normoxia conditions. However, under hypoxia, the expression of MT proteins was up-regulated in PC-3 cells but was not changed in LNCaP cells (Fig. 1B).

Cell growth inhibition and apoptosis induction caused by down-regulation of $M T-2 A$. The growth rates of hypoxic LNCaP and PC-3 cells decreased to about two thirds of that under normoxia (Fig. 2B). Flow cytometry analysis, performed to identify the specific point of cell cycle alteration, found that hypoxic LNCaP and PC-3 cells experienced a reduction in the number of $\mathrm{G} 1$ phase cells and an increase in cells in the sub-G1 region (Fig. 2C). To investigate the effect of MT on cell proliferation, cell growth was analyzed after MT-2A knockdown with siRNA. The siRNA-MT2A treatment decreased MT protein levels to $<30 \%$ by densitometric analysis of wild-type, while the siRNA-NC treatment produced no effects under either of the $\mathrm{O}_{2}$ conditions in $\mathrm{LNCaP}$ and PC-3 cells (Fig. 2A). siRNA-MT2A treatment significantly inhibited growth of LNCaP and PC-3 cells by about $20 \%$ at 48 and $72 \mathrm{~h}$ under hypoxia $(\mathrm{p}<0.05)$. Although treatment with siRNA-MT2A also inhibited the proliferation of $\mathrm{LNCaP}$ cells under normoxia by $20 \%$ (48 and $72 \mathrm{~h}$ ) (p<0.05), PC-3 cell growth was inhibited by only $10 \%$ (48 and $72 \mathrm{~h}$ ) under normoxia $(\mathrm{p}<0.05)$ (Fig. 2B). Flow cytometry analysis revealed an increase of cells in the sub-G1 region in siRNA-MT2A treated $\mathrm{LNCaP}$ and $\mathrm{PC}-3$ compared to the control or siRNA-NC treated cells (Fig. 2C). To determine whether the increase of sub-G1 cells was caused by apoptosis, poly(ADPribose) polymerase (PARP) cleavage was analyzed in both cell lines under hypoxia (Fig. 2D). Cleaved PARP was detected more intensively under hypoxia than under normoxia in both LNCaP and PC-3 cells. The siRNA-NC treatment did not increase the amount of cleaved PARP under either normoxia or hypoxia. However, cleavage of PARP did increase in both cell lines treated with siRNA-MT2A.

Immunohistochemical localization of MT in human prostate cancer tissues. MT protein expression was examined in human prostate cancer using paraffin-embedded tissue sections obtained from patients undergoing radical prostatectomy $(n=40)$, with $(n=20)$ and without $(n=20)$ neoadjuvant androgen ablation therapy (Fig. 3). The clinicopathological variables are shown in Table III. The patient characteristics were not significantly different between patients with and without androgen ablation therapy. In the sample without androgen ablation therapy, intense MT staining was observed in prostate cancer cells (Fig. 3B). In contrast, weak or moderate staining was displayed in the cytoplasm of the lining of acinar cells in normal prostate tissue (Fig. 3A). The basal cell layer and the stromal cells were negative for MT staining. The sample with androgen ablation therapy showed intense staining for MT in residual cancer cells (Fig. 3D), but normal tissue was atrophied and unstained (Fig. 3C). The overall distribution of MT staining intensity defined as negative, weak, moderate, and strong is shown in Fig. 3E. MT expression was significantly increased in cancer cells compared to normal prostate tissue in both the groups with $(\mathrm{p}<0.001)$ and without $(\mathrm{p}<0.001)$ androgen ablation therapy. There were no significant differences in staining intensity of cancer cells between patients with and without androgen ablation therapy.

\section{Discussion}

Tumor cells undergo a variety of biological responses when placed in hypoxic conditions, including activation of signaling pathways and drastic changes in gene expression patterns 
Table III. Patient characteristics.

\begin{tabular}{|c|c|c|c|}
\hline Characteristic & $\begin{array}{l}\text { Androgen ablation } \\
\text { therapy }(-)(n=20)\end{array}$ & $\begin{array}{l}\text { Androgen ablation } \\
\text { therapy }(+)(\mathrm{n}=20)\end{array}$ & $\mathrm{P}$-value \\
\hline Median age (years) & $69(57-74)$ & $70(57-75)$ & $0.976^{\mathrm{a}}$ \\
\hline Median PSA (ng/ml) & $9.7(4.0-33.0)$ & $9.3(4.7-90.0)$ & $0.298^{\mathrm{a}}$ \\
\hline \multicolumn{4}{|l|}{ Pathology } \\
\hline Median Gleason score & $6(3-8)$ & $7(4-10)$ & $0.527^{\mathrm{a}}$ \\
\hline Differentiation (number of patients) & & & $0.570^{\mathrm{b}}$ \\
\hline Well & 8 & 7 & \\
\hline Moderately & 10 & 9 & \\
\hline Poorly & 2 & 4 & \\
\hline Median term of androgen ablation therapy (months) & - & $5(3-18)$ & \\
\hline
\end{tabular}

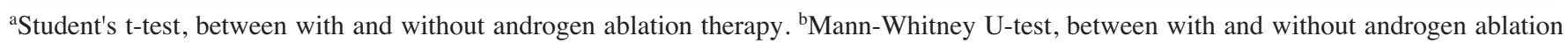
therapy.

that enable them to better survive in a suboptimal $\mathrm{O}_{2}$ environment and even increase their potential aggression $(2,3)$. Tumor hypoxia exists in human prostate cancer tissue and correlated with a poor outcome of prostate cancer (8-11). The aim of this study was to define the hypoxia inducible genes in human prostate cancer cells and to explore these genes as a novel target of therapy for human prostate cancer. In this study, we analyzed the hypoxia inducible genes by cDNA microarray and identified MT. To explore MT as a novel target of therapy, we investigated the effect of MT suppression on human prostate cancer cells growth and the MT expressions in human prostate cancer tissue and residual cancer cells after androgen ablation therapy. The down-regulation of MT by siRNA resulted in inhibition of cell growth and induced apoptosis. MT was overexpressed in human prostate cancer tissue and residual cancer cells after androgen ablation therapy. Results of this study indicate that MT may be a new molecular target for the treatment of human prostate cancer.

Oxygen electrode studies, using the Eppendorf probe, have recently demonstrated the presence of significant hypoxia within human prostate cancer $(8,9,11)$. According to Movsas et al, tissue oxygen concentrations in human prostate cancer range between 2.3 and $7.3 \mathrm{mmHg}$ significantly lower than in normal muscle $(28.8 \mathrm{mmHg})$. In this study, the microenvironments of clinical prostate cancer cells were recreated by culturing prostate cancer cell lines at $0.5 \% \mathrm{O}_{2}$, which is equal to $3.8 \mathrm{mmHg}$ of $\mathrm{PO}_{2}$.

In cDNA microarray analysis, several tumor suppressor genes were down-regulated by hypoxia, including maspin. Abraham et al reported that maspin, member of the serine protease inhibitor family, decrease the tumorigenic and metastatic potential of PC cells (16). The down-regulation of maspin under hypoxia may be involved in acquisition of malignant potential of hypoxic PC cells. On the other hand, 6 genes (Nip3, DCC, c-fos, c-jun, VEGF and MT) were upregulated remarkably under hypoxia. Fluorescent intensities of DCC and c-fos were very weak under normoxia, so slight changes of these mRNAs might significantly affect the results.
Although MT was the third up-regulated gene, it was strongly expressed and is thought to have important roles in the human prostate. Consequently, the expression and roles of MT in prostate cancer cells were investigated under hypoxia in subsequent experiments.

The MTs are a group of low-molecular weight (6-7 kDa), cysteine rich intracellular proteins, that are encoded by a family of genes containing at least 10 functional isoforms, MT-1A, 1B, 1E, 1F, 1G, 1H, 1X, 2A, 3 and 4, in human. Among these subtypes, the expression of MT-1 and MT-2 isoform specific mRNA has been reported in human prostate cancer cell lines as well as in this study. Several lines of evidence suggest a role for MT in carcinogenesis, cancer development, treatment resistance and prognosis $(13,14,17,18)$.

It was reported that MT is induced by hypoxia in human squamous carcinoma cells (19). This report is the first demonstration that MT-1X and MT-2A are up-regulated under hypoxia in human prostate cancer cells. In LNCaP cells, MT protein expression was not changed under hypoxia, whereas MT-1X and MT-2A transcripts were up-regulated under hypoxia. The reason for this dissociation was suggested to be that the anti-MT antibody detects both MT isoforms which were up-regulated and down-regulated. The mechanisms of MT up-regulation by hypoxia have not been well documented. The promoter of human MT-2A contains a glucocorticoidresponsive element, Sp1, AP1 and AP2 binding sites, and metal response elements (20). In our cDNA microarray analysis, c-fos and c-jun are also induced in LNCaP cells by hypoxia. c-Fos and c-Jun are AP1 transcription factors that are reportedly induced by hypoxia in other cell lines $(21,22)$. As the promoter of human MT-2A contains an AP1 binding site (20), MT-2A may be up-regulated by hypoxia via AP1 in human prostate cancer cells.

Previous studies have demonstrated that MT can confer resistance to radiation and anticancer drugs such as cisplatin (23-25). Kondo et al showed that MT null cells have increased sensitivity to anticancer drugs (26) and Dutta et al reported that overexpression of MT-3 influences the chemotherapeutic 
drug resistance of $\mathrm{PC}-3$ (27), such that MT induction by hypoxia may be one of the factors involved in the chemotherapeutic resistance of hypoxic cancer cells.

In this study, treatment with siRNA-MT2A inhibited the cell growth of hypoxic PC-3 and of normoxic and hypoxic LNCaP by about $20 \%$. In contrast, the growth rate of PC-3 treated with siRNA-MT2A decreased by only $10 \%$ under normoxic conditions. This difference may be due to the lower expression levels of MT protein in normoxic PC-3 cells. These findings suggest that the degree of cell proliferation may depend on the amount of MT expression in human prostate cancer cells. As shown in this study, inhibition of cell growth after treatment with siRNA-MT2A may be due to the induction of apoptosis in prostate cancer cells. Kondo et al reported that MT null mouse embryonic cells are more susceptible to apoptotic death than are wild-type mouse embryonic cells (28). Abdel-Mageed et al showed that down-regulation of MT with specific antisense oligonucleotides can result in growth arrest and induction of apoptosis in breast carcinoma cells that overexpress MT (29). They described the mechanism of growth arrest and apoptosis as the result of changes in the expression patterns of the bcl-2, c-myc, c-fos and p53 genes. Zinc is an abundant metal in the human prostate that reportedly inhibits human prostate cancer cell growth and induces apoptosis $(30,31)$. As MT binds zinc and acts as a zinc store in prostate cells (14), down-regulation of MT may induce zinc isolation, and this isolated zinc may inhibit cell growth and induce apoptosis.

It was recently reported that intense MT staining is observed in cancer cells, while epithelium staining is patchy in normal human prostate tissue (32). A positive correlation of MT expression with Gleason grade has also been reported (33). The immunohistochemical results of this study, that MT staining is more intense in cancer cells than in normal epithelium, are consistent with the previous report. Furthermore, intense MT staining was still observed in residual cancer cells after androgen ablation therapy, while expression of MT was reduced in the normal gland. To our knowledge, this is the first report on MT expression in the human prostate after androgen ablation therapy.

Androgen ablation causes prostate cancer regression because without androgen, the rate of cell proliferation is lower and the rate of cell death is increased, leading to extinction of these cells (34). Furthermore, it has been suggested that androgen ablation therapy induces a reduction in blood flow, hypoxia and apoptosis in prostate gland (3537). Buttyan et al proposed the concept that hypoxia in prostate tumors induced by androgen ablation therapy is implicated not only in the treatment of prostate cancer but is also the reason why prostate tumors ultimately become unresponsive to androgen ablation therapy (38). These results suggest that MT overexpressed cancer cells escape from apoptosis induced by androgen ablation therapy. Downregulation of MT expression by siRNA may prove useful for the enhancement of apoptosis induced by androgen ablation therapy in the residual prostate cancer cells.

In vitro experiments using human prostate cancer cell lines have shown that increased expression of hypoxia inducible factor-1, a transcription factor that coordinates the cellular response to hypoxia, is associated with an increased growth rate, differentiation and apoptotic sensitivity (39). Park et al showed that hypoxia increases activity of androgen receptor which plays a critical role in the development, progression, and treatment response of prostate cancer (40). These reports provide evidence that there are many elements of the hypoxiaresponse pathway which associate with acquisition of the malignant phenotype and aggressive tumor behavior. Our results may indicate that MT is one of the elements of the hypoxia-response pathway.

In conclusion, MT was up-regulated under hypoxia in prostate cancer cells and overexpressed in prostate cancer tissue and residual cancer cells after androgen ablation therapy. Down-regulation of MT by siRNA inhibited cell growth and induced cell death. MT may be a new molecular target for the treatment of human prostate cancer.

\section{Acknowledgements}

We are grateful to Noriko Hamamatsu, Yasuko Ayaki, and Yasuhiro Sumino for technical supports.

\section{References}

1. Gronberg H: Prostate cancer epidemiology. Lancet 361: 1048-1053, 2003.

2. Hockel M and Vaupel P: Tumor hypoxia: definitions and current clinical, biologic and molecular aspects. J Natl Cancer Inst 93: 266-276, 2001.

3. Harris AL: Hypoxia - a key regulatory factor in tumour growth. Nat Rev Cancer 2: 38-47, 2002.

4. Janssen AM, van Duijn W, Kubben FJ, et al: Prognostic significance of metallothionein in human gastrointestinal cancer. Clin Cancer Res 8: 1889-1896, 2002.

5. Hockel M, Schlenger K, Aral B, Mitze M, Schaffer U and Vaupel P: Association between tumor hypoxia and malignant progression in advanced cancer of the uterine cervix. Cancer Res 56: 4509-4515, 1996.

6. Nordsmark M, Overgaard M and Overgaard J: Pretreatment oxygenation predicts radiation response in advanced squamous cell carcinoma of the head and neck. Radiother Oncol 41: 31-39, 1996.

7. Brizel DM, Scully SP, Harrelson JM, Layfield LJ, Bean JM, Prosnitz LR and Dewhirst MW: Tumor oxygenation predicts for the likelihood of distant metastases in human soft tissue sarcoma. Cancer Res 56: 941-943, 1996.

8. Movsas B, Chapman JD, Greenberg RE, et al: Increasing levels of hypoxia in prostate carcinoma correlate significantly with increasing clinical stage and patient age: an Eppendorf $\mathrm{pO}(2)$ study. Cancer 89: 2018-2024, 2000.

9. Movsas B, Chapman JD, Hanlon AL, et al: Hypoxic prostate/ muscle pO2 ratio predicts for biochemical failure in patients with prostate cancer: preliminary findings. Urology 60: 634-639, 2002 .

10. Hochachka PW, Rupert JL, Goldenberg L, Gleave M and Kozlowski P: Going malignant: the hypoxia-cancer connection in the prostate. Bioessays 24: 749-757, 2002.

11. Movsas B, Chapman JD, Horwitz EM, et al: Hypoxic regions exist in human prostate carcinoma. Urology 53: 11-18, 1999.

12. Hasumi M, Suzuki K, Matsui H, Koike H, Ito K and Yamanaka H: Regulation of metallothionein and zinc transporter expression in human prostate cancer cells and tissues. Cancer Lett 200: 187-195, 2003.

13. Lazo JS and Pitt BR: Metallothioneins and cell death by anticancer drugs. Annu Rev Pharmacol Toxicol 35: 635-653, 1995.

14. Miles AT, Hawksworth GM, Beattie JH and Rodilla V: Induction, regulation, degradation, and biological significance of mammalian metallothioneins. Crit Rev Biochem Mol Biol 35: $35-70,2000$.

15. Mizzen CA, Cartel NJ, Yu WH, Fraser PE and McLachlan DR: Sensitive detection of metallothioneins-1, -2 and -3 in tissue homogenates by immunoblotting: a method for enhanced membrane transfer and retention. J Biochem Biophys Methods 32: $77-83,1996$. 
16. Abraham S, Zhang W, Greenberg $\mathrm{N}$ and Zhang $\mathrm{M}$ : Maspin functions as tumor suppressor by increasing cell adhesion to extracellular matrix in prostate tumor cells. J Urol 169: 1157-1161, 2003.

17. Cherian MG, Jayasurya A and Bay BH: Metallothioneins in human tumors and potential roles in carcinogenesis. Mutat Res 533: 201-209, 2003.

18. Theocharis SE, Margeli AP, Klijanienko JT and Kouraklis GP Metallothionein expression in human neoplasia. Histopathology 45: 103-118, 2004.

19. Murphy BJ, Laderoute KR, Chin RJ and Sutherland RM: Metallothionein IIA is up-regulated by hypoxia in human A431 squamous carcinoma cells. Cancer Res 54: 5808-5810, 1994.

20. Skroch P, Buchman C and Karin M: Regulation of human and yeast metallothionein gene transcription by heavy metal ions. Prog Clin Biol Res 380: 113-128, 1993.

21. Muller JM, Krauss B, Kaltschmidt C, Baeuerle PA and Rupec RA: Hypoxia induces c-fos transcription via a mitogen-activated protein kinase-dependent pathway. J Biol Chem 272: 23435-23439, 1997.

22. Ausserer WA, Bourrat-Floeck B, Green CJ, Laderoute KR and Sutherland RM: Regulation of c-jun expression during hypoxic and low-glucose stress. Mol Cell Biol 14: 5032-5042, 1994.

23. Cai L, Satoh M, Tohyama C and Cherian MG: Metallothionein in radiation exposure: its induction and protective role. Toxicology 132: 85-98, 1999.

24. Satoh M, Cherian MG, Imura N and Shimizu H: Modulation of resistance to anticancer drugs by inhibition of metallothionein synthesis. Cancer Res 54: 5255-5257, 1994.

25. Kondo Y, Kuo SM, Watkins SC and Lazo JS: Metallothionein localization and cisplatin resistance in human hormoneindependent prostatic tumor cell lines. Cancer Res 55: 474-477, 1995.

26. Kondo Y, Woo ES, Michalska AE, Choo KH and Lazo JS: Metallothionein null cells have increased sensitivity to anticancer drugs. Cancer Res 55: 2021-2023, 1995.

27. Dutta R, Sens DA, Somji S, Sens MA and Garrett SH: Metallothionein isoform 3 expression inhibits cell growth and increases drug resistance of PC-3 prostate cancer cells. Prostate 52: 89-97, 2002.

28. Kondo Y, Rusnak JM, Hoyt DG, Settineri CE, Pitt BR and Lazo JS: Enhanced apoptosis in metallothionein null cells. Mol Pharmacol 52: 195-201, 1997.
29. Abdel-Mageed AB and Agrawal KC: Antisense down-regulation of metallothionein induces growth arrest and apoptosis in human breast carcinoma cells. Cancer Gene Ther 4: 199-207. 1997.

30. Liang JY, Liu YY, Zou J, Franklin RB, Costello LC and Feng P: Inhibitory effect of zinc on human prostatic carcinoma cell growth. Prostate 40: 200-207, 1999.

31. Feng P, Li TL, Guan ZX, Franklin RB and Costello LC: Direct effect of zinc on mitochondrial apoptogenesis in prostate cells. Prostate 52: 311-318, 2002.

32. Garrett SH, Sens MA, Shukla D, Flores L, Somji S, Todd JH and Sens DA: Metallothionein isoform 1 and 2 gene expression in the human prostate: down-regulation of MT-1X in advanced prostate cancer. Prostate 43: 125-135, 2000.

33. Moussa M, Kloth D, Peers G, Cherian MG, Frei JV and Chin JL: Metallothionein expression in prostatic carcinoma: correlation with Gleason grade, pathologic stage, DNA content and serum level of prostate-specific antigen. Clin Invest Med 20: 371-380, 1997.

34. Denmeade SR, Lin XS and Isaacs JT: Role of programmed (apoptotic) cell death during the progression and therapy for prostate cancer. Prostate 28: 251-265, 1996.

35. Shabsigh A, Ghafar MA, De la Taille A, Burchardt M, Kaplan SA, Anastasiadis AG and Buttyan R: Biomarker analysis demonstrates a hypoxic environment in the castrated rat ventral prostate gland. J Cell Biochem 81: 437-444, 2001.

36. Okihara K, Watanabe $\mathrm{H}$ and Kojima M: Kinetic study of tumor blood flow in prostatic cancer using power Doppler imaging. Ultrasound Med Biol 25: 89-94, 1999.

37. Buttyan R, Shabsigh A, Perlman H and Colombel M Regulation of apoptosis in the prostate gland by androgenic steroids. Trends Endocrinol Metab 10: 47-54, 1999.

38. Anastasiadis AG, Stisser BC, Ghafar MA, Burchardt M and Buttyan R: Tumor hypoxia and the progression of prostate cancer. Curr Urol Rep 3: 222-228, 2002.

39. Ghafar MA, Anastasiadis AG, Chen MW, et al: Acute hypoxia increases the aggressive characteristics and survival properties of prostate cancer cells. Prostate 54: 58-67, 2003.

40. Park SY, Kim YJ, Gao AC, et al: Hypoxia increases androgen receptor activity in prostate cancer cells. Cancer Res 66: 5121-5129, 2006. 